\title{
Principles of Conservation of Biodiversity in Hydrobiocenoses Formed as a Result of Carbon and Energy Enterprises
}

\author{
Ludmila Zakonnova*, Igor Nikishkin ${ }^{2}$, Ludmila Stemplewska ${ }^{3}$, and Alena Chupryakova ${ }^{1}$ \\ ${ }^{1}$ T.F. Gorbachev Kuzbass State Technical University, Belovo Branch, 65264466 Ilyica st. 32, Belovo, \\ Russia \\ ${ }^{2}$ Belovsky Fisheries LLC, Belovo, Russia \\ ${ }^{3}$ Vistula Academy of Finance and Business in Warsaw, 3 Stokłosy Str., 02-787 Warsaw, Poland
}

\begin{abstract}
This paper presents the principles developed by the authors for the operation of reservoirs of technogenic origin, formed as a result of the activities of coal mining and energy enterprises, which can become basic when developing models for the rational use of wastewater and land from coal mining regions: maximum environmental friendliness, reasonable technological (biotechnological) restrictions, forecasting and regulation ecological consequences of the introduction of alien objects of ichthyofauna, etc. The expediency of soft biological methods for cleaning eutrophic water bodies is substantiated. As part of the implementation of the principle of forecasting and regulating the environmental consequences of the introduction of alien fauna ichthyofauna, a new approach is proposed to create a model of variability of the hydroecosystem that will allow developing mechanisms to maintain ecological balance in water bodies and coordinate the work of hatcheries and fishing enterprises, environmental monitoring services and other institutions. The principles of a reasonable biotechnological restriction in the operation of a reservoir and the possibility of alternative use of a reservoir have found their application in the development of warm-water aquaculture using waste warm water. It is proved that the principles of operation of reservoirs of technogenic origin, formed as a result of the activities of coal mining and energy enterprises, may well be successfully implemented to preserve biological diversity in large technogenic reservoirs.
\end{abstract}

\section{Introduction}

The global achievements of civilization to one degree or another are due to anthropogenic environmental crises and the technological revolutions that followed, which completed the phase of the exclusively biological existence of the species Homo sapiens.

The first and second agricultural (biotechnological) revolutions that led to intensive agricultural practices were caused by crises of reducers and consumers. Intensive farming, which demanded innovative tools and mineral resources from humanity, provoked an

\footnotetext{
* Corresponding author: nir belovo@mail.ru
} 
industrial revolution, which grew into a scientific and technical one.

The modern crisis of reducers, as a result of the irrational use of the achievements of the scientific and technological revolution, accompanied by the introduction of a huge number of xenobiotics into the environment, threatens the catastrophic consequences of a biosphere scale. In this regard, the construction of predictive models of rational use of both global and local ecosystems is more relevant than ever.

Of particular interest in this regard are the anthropogenic ecosystems: urbabiogeocenoses, agrocenoses, hydroecocenoses formed as a result of the activities of coal mining, energy and other enterprises. The leading problem of artificial ecosystems is maintaining ecological balance in them, which is very complicated by the destruction of natural biogeocenoses: reducing biodiversity and shortening trophic chains disrupts the existing processes of biogenic migration of matter and energy, which leads to instability and degradation of both individual elements and the ecosystem as a whole.

The medium-term prospects of spent and operated technological reservoirs can be considered in two aspects: degradation and uncontrolled succession processes, or the formation of a stable hydroecosystem that meets Ashby's law, which will allow this reservoir to be used after decommissioning by an industry enterprise, at least in recreational ones, and as a maximum - for agricultural purposes.

The prospects of each man-made reservoir should be evaluated individually, according to the results of monitoring the state of hydrobiogeocenosis by the most appropriate methods. Modern monitoring tools ensure the use of remote sensing methods instead of expensive direct measurements, which allows more accurate and dynamic forecasting of the development of aquatic ecosystems, both natural and anthropogenic origin $[3 ; 4 ; 12-15]$. At the same time, in the study of the environmental problems of small technogenic reservoirs of coal-mining and coal-processing regions, methods of direct monitoring and experimental testing of methods for their cleaning are still relevant.

\section{Materials and methods}

This paper presents the principles developed by the authors for the operation of reservoirs of technogenic origin, formed as a result of the activities of coal mining and energy enterprises, which can become basic in developing models for the rational use of wastewater and land from coal mining regions.

1. Maximum environmental friendliness of the processes of operation by an enterprise of the industry, which allows preserving natural diversity.

2. Reasonable technological (biotechnological) limitations in the operation of a reservoir.

3. The possibility of alternative use of the reservoir after its decommissioning by an industry enterprise.

4. The priority of biological treatment methods.

5. Prediction and regulation of the environmental consequences of the introduction of alien fauna objects.

To assess the feasibility of implementing the developed principles, two types of water bodies were chosen as model objects: a small, non-flowing water body that does not have physical contacts with the regional hydroecosystem, and a large water body that is part of the hydroecosystem and formed as a result of regulation of river flow. Such reservoirs became: the reservoir-cooler of the Belovskaya TPP (Belovskoye Sea) and Lake Tolstochikha - a flooded coal mine.

\section{Results and discussion}

Tolstochikha lake. The coordinates of the reservoir 54.283635, 86.004803. The pond was 
formed as a result of flooding the spent quarry. Its dimensions are $778 \times 378 \times 72 \mathrm{~m}$.

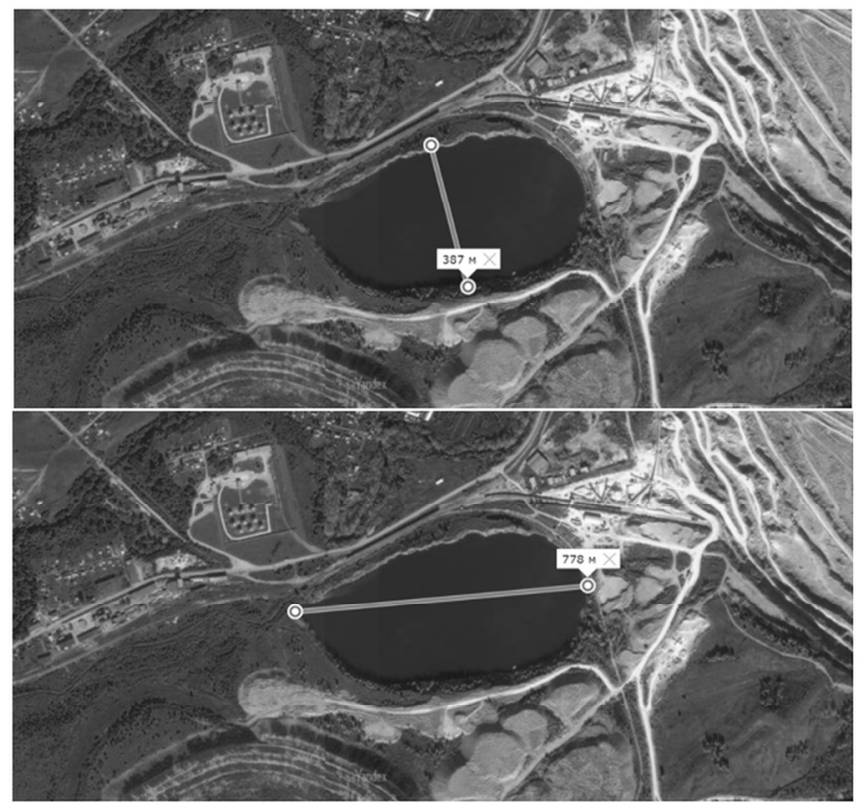

Fig. 1. Tolstochikha Lake.

The age of the lake is approximately 30 years, under the water there is a flooded railway. Until recently, it was used for recreational purposes (fishing, swimming, etc.). In 2016, swimming and fishing were prohibited. Hydrochemical analysis of water samples taken by us in the coastal zone revealed a high content of humic acids characteristic of swamped water bodies. Hydrobiological analysis showed the presence of representatives typical for water bodies in the initial stage of eutrophication: cyclops, daphnia, Bosmin, ciliates Suvoyka. All this made it possible to draw a preliminary conclusion about the processes of eutrophication beginning in the reservoir, therefore the ban on the use of Lake Tolstochikha for recreational purposes is quite justified. The small size of the reservoir does not make it possible to use it in agriculture, for example, for intensive aquaculture management. The possibility of the formation of a more or less stable biocenosis through artificial introduction of hydrobionts is doubtful.

Thus, the majority of small local non-flowing technogenic reservoirs are not very suitable for re-exploitation, therefore, reclamation measures in the case of such reservoirs are mainly unprofitable and impractical. Depending on the location of such reservoirs, separately for each, consideration should be given to the possibility of drainage in order to combat the vulture that inevitably appears in eutrophic reservoirs.

The cooler pond of the Belovskaya GRES, is part of the Ob basin, created by regulating the flow of the Inya river in 1964, operates on a reverse water supply system, the design reservoir area is 1300 hectares, currently 1430 hectares, the water volume is $47.9 \times 106 \mathrm{cbm}$ The reservoir is inhabited by 17 aquatic and 7 introduced fish species introduced during the existence of the reservoir: carp (carp), grass carp, white carp, motley silver carp (and their hybrids), channel catfish, black and large buffalo. All of the above listed species of introducers entered the reservoir from the Belovskoye warm-water fisheries (LLC Belovskoye Fisheries). Isolated cases of catching exotic fish entering the reservoir as a result of unauthorized stocking by amateur aquarists were noted. 


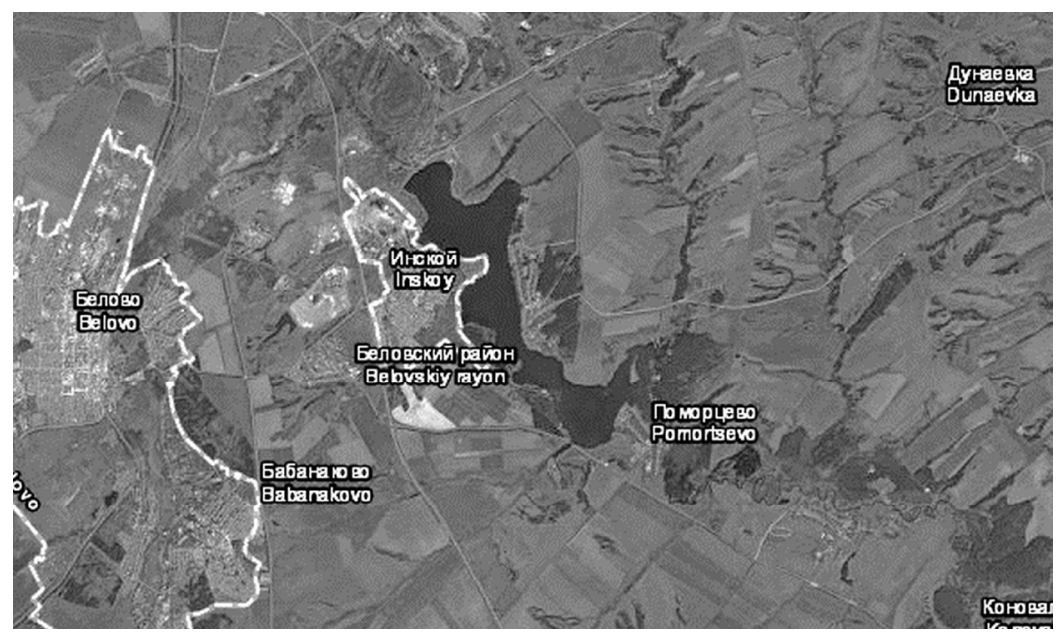

Fig. 2. Reservoir-cooler Belovskaya TPP.

At the initial stage of operation, the anthropogenic load on the reservoir was mainly due to technological discharges of the Belovskaya state district power station. In subsequent years, in connection with the expansion of the functions of the reservoir, three groups of pollutants were distinguished.

1. Technological, due to the work of the Belovskaya TPP, coal enterprises and farmland: emissions of the Belovskaya TPP: heat, oil products, alkali when cleaning boilers, the use of chemical reagents; discharges into the Inya River and its groundwater inflows from the Permyakovsky, Zadubrovsky, Vinogradovsky, Karakansky, Yevtinsky sections of heavy metals, phenols, etc. (discharges into underground aquifers are not excluded); organic washes from the fields of the villages of Mencherep, Korotkovo, Pomortsevo. In the first and second cases, the introduction of modern wastewater treatment methods can be an effective measure to reduce pollution.

2. Fish breeding load on the reservoir due to both representatives of the ichthyofauna freely living in the reservoir and aquaculture objects. Belovo fisheries should be recognized as epidemiologically successful. Due to strict observance of sanitary and epidemiological standards and timely preventive measures for the entire period of work at the fish farm, not a single case of fish disease with viral diseases was recorded.

The main pollutants are fish feces, undigested fish feed residues leading to siltation of the bottom in the fishery. Pollution reduction measures: use of high-quality feed with low feed ratios, improvement of aquaculture management technology.

3. Housing and communal and recreational. On the shore of the reservoir there are numerous pensions, recreation centers, urban settlements. Inskoy, the treatment plant of which is located near the water protection zone. Pollution reduction measures: elimination of solid waste dumps in the water area of the reservoir, introduction of modern technologies for domestic wastewater treatment.

Research by a number of scientists, including V.V. Kirillov and co-authors made it possible to assess the level of production and destruction processes in the cooling reservoir of the Belovskaya TPP, to assess the current state of zoobenthos and zooperiphyton and higher aquatic vegetation of the reservoir and compare the data with the results of other authors $[2 ; 3 ; 6 ; 9]$. As a result of the high anthropogenic load, the reservoir was eutrophied, and therefore there was a danger that detritus, settling on the condenser tubes of the state district power station, would reduce the degree of water cooling. 
We have studied two approaches to the problem of reducing the eutrophication of a reservoir: technological and environmental. Taking into account that according to Valentin Aleksandrovich Smirnov and co-authors, the species diversity index of the Belovsky reservoir reaches 3.2-3.5, the use of herbicides (technological approach) can lead to the death of many species of aquatic organisms and the degradation of the reservoir. Therefore, the fight against further eutrophication of the reservoir was carried out using mild ecological methods, among which the use of herbivorous fish, silver carp and grass carp, to combat plankton and higher aquatic vegetation, according to the developed fish-biological base. As a result of measures taken over the past 20 years, the eutrophication of the reservoir has been suspended. Thus, the principles of maximum environmental friendliness of the operation processes and the use of soft biological cleaning methods formulated by us have found their practical application.

In the process of solving the problem of eutrophication, a method of cleaning the reservoir with the help of ameliorator fish - silver carp and grass carp was used. Both of these species are not endemic. Therefore, there was a danger of the negative consequences of the introduction of invading fish into the reservoir: alien fish species, integrated into hydrobiocenoses, can compete with native forms, thereby changing the structure of the ecosystem as a whole. And then the planned positive effect of the introduction can be offset by the negative impact of the factors accompanying this introduction. In ecologically disadvantaged regions, for example, in the Kuzbass, the water bodies of which are part of the $\mathrm{Ob}$ basin, such a synergistic effect can affect the ecological state of the region as a whole.

In the framework of the principle of predicting and regulating the environmental consequences of the introduction of alien fauna of ichthyofauna, the authors propose a new approach to creating a model of variability of the hydroecosystem of the $\mathrm{Ob}$ basin after the anthropogenic introduction of reclamation fish and other alien aquaculture objects, which will allow developing mechanisms for maintaining ecological balance in water bodies and coordinating the work of fish breeding and fishing enterprises, environmental monitoring services and other institutions.

It has been established that introduced fish, in connection with the peculiarity of their nutrition, are not food competitors to indigenous species. Growing them in a pond will not reduce the production of local fish species. Due to the peculiarities of reproduction, the accidental departure of a silver carp into the river system will not lead to a naturalization of the species and a spontaneous increase in numbers due to natural reproduction.

And, finally, the principles of reasonable biotechnological restrictions on the operation of a reservoir and the possibility of alternative uses of a reservoir have found their application in the development of warm-water aquaculture using waste warm water. One of the measures to preserve the biodiversity of fish in natural waters can be expanded production of fish products by intensive methods in industrial fish breeding enterprises. Both native species and introduced species and breeds of domesticated forms of fish, such as, for example, Cyprinus carpio carpio carp, which have undergone successful breed testing under new conditions, can become objects of fish breeding.

LLC Belovskoye Fisheries LLC, which relates to industrial-type fisheries, is successfully coping with this problem; by temperature, it belongs to the group of warm-water farms. Maximum productivity - 1000 tons of salable fish per year. Currently, Belovsky Fisheries LLC specializes in breeding and growing carp, white and colorful silver carp, grass carp, channel catfish, and trout. Commercial sturgeon is grown from imported planting material. Fish stock comes from Krasnodar Territory, Moscow and Rostov Regions. 


\section{Conclusion}

Thus, the given example proves that the principles of exploitation of reservoirs of technogenic origin, formed as a result of the activities of coal mining and energy enterprises, may well be successfully implemented to preserve biological diversity in large technogenic reservoirs.

\section{References}

1. A. Akiyama, Bull. Jap. Soc. scient. Fish, 36, 563-570 (1970)

2. C. Bronson, Technical Bulletin, 3, 2-4 (2002)

3. N. Cazzaniga, Biocell, 26, 71-81 (2002)

4. A. Collin, J. Hench, Remote Sensing.4(12),1425-1447 (2012)

5. M. Deidda, G. Sanna, Proceedings of the XXII ISPRS Congress. Melbourne, Australia, 153-157 (2012)

6. A. Estebenet, P. Martin, Biocell, 26(1), 83-89 (2002)

7. H. Gordon, W. McCunley, Applied Optics, 14(2),413-416 (1975)

8. C. Hazel, S. Meith,Water Proj. Branch. Lab. Rep. July 16, 1-8 (1969)

9. A. Hutorowicz A., Hutorowicz J. Ecological Questions, 9, 79-86 (2008)

10. A. Kanno, Y. Koibuchi, M. Isobe, IEEE Geoscience and Remote Sensing Letters, 8(1), 64-67 (2011)

11. A. Matsukura, H. Tsumuki, Y. Izumi, T. Wada, Exp. Biol, 212, 258-256 (2009)

12. J. McKim, D. Benoit, J. Fish. Res. Board Can, 28, 655-662 (1971)

13. A. Minghelli-Roman, A. Goreac, S. Mathieu, M. Spigai, P, Gouton, International Journal of Remote Sensing, 30 (1-2), 5737-5750 (2009)

14. S. Sathyendranath S. IOCCG Report Number 3. Dartmouth, Canada: MacNab Print, 3,140 (2000)

15. R. Uma Maheswari R. International Journal of Marine Science, 3(11), (2013) 